\title{
Outcome of scalp reconstruction in a teaching hospital
}

\author{
MT Islam¹, SN Abdullah², MM Newaz ${ }^{3}$, M Rahman4, MA Rahman $^{5}$
}

\begin{abstract}
An area of loss of scalp could be covered by various methods including local flap, distant flaps, skin graft, free flap surgery or tissue expansion. Each method has some disadvantages, such as postoperative alopecia or donor site morbidities. The study was conducted in the Department of Burn and Plastic Surgery, Khulna Medical College Hospital from July 2011 to June 2015. Scalp reconstruction was performed on 16 patients who sustained scalp loss from RTA, surgery for cancer, burn injuries and machinery injury. The size of the wound ranged from $6 \mathrm{~cm} 2$ to $320 \mathrm{~cm} 2$. Transposition flap, rotation flap, removal of osteomyelitic bone and skin grafts were done. Among 16 cases, 3 cases (18.75\%) were skin grafted, 6 cases (37.5\%) were reconstructed with transposition flaps, 5 cases (31.25\%) were reconstructed with rotation flap and 2 cases (12.5\%) were reconstructed with skin graft after removal of osteomyelitic outer table of skull bone. The postoperative complications seen in this series includes partial graft loss in 2 cases (skin graft), marginal necrosis in 1 case (transposition flap) and alopecia in 11 cases (in skin graft and transposition flap). There was no alopecia in reconstruction with rotation flap. Rotation flaps brings the best outcome in terms of durability and aesthetic acceptability where it is applicable in comparison to other procedure.
\end{abstract}

Bang Med J Khulna 2015; 48 : 3-6

\section{Introduction}

The scalp is unique as structure, shape and location. It is the highest point of the body, most exposed and usually uncovered by clothing.' Coverage of the scalp defect due to different causes may often be challenging. The skin of the scalp lacks laxity and primary closure of wounds greater than $2 \mathrm{~cm}$ is often not possible. ${ }^{1}$ Anatomically, it is described as an organ based on a rigid, flat aponeurosis and consisting in thick skin, penetrated by hair, nourished by a rich vascular network, situated in the subcutaneous tissue. ${ }^{2}$ The scalp has a rich vascular supply; the ability to withstand wounds of greater tension than other regions, and often has hair that can camouflage resulting scars or asymmetries. Nevertheless, most of the scalp is relatively inelastic; repair of even small defect is difficult. These properties compromise the ease of effective reconstruction and affect the surgeon's ability to reconstruct defects in this area. Therefore the decision making process behind a successful outcome requires a solid knowledge of anatomy, a clear evaluation of the defect and the knowledge of a variety of reconstructive options available.

Multiple reconstructive options exist that include, primary wound repair, healing by secondary intention, use of skin grafts, local flaps, regional myocutaneous flaps, and micro vascular free flaps, tissue expansion. While considering reconstructive options the plan must always be tailored to the individual patient's needs and due attention be given to the aesthetic outcome that specially includes preservation of the hairline and hair follicle orientation, scar camouflage, avoidance of alopecia. ${ }^{1}$

\section{Material and methods}

This prospective observational study was conducted in the Department of Burn and Plastic Surgery, Khulna Medical College Hospital from July 2011 to June 2015. During the study period reconstruction of scalp was done in 16 patients who sustained scalp loss from RTA, surgery for cancer, burn injuries and machinery injury. The size of the wound ranged from $6 \mathrm{~cm}^{2}$ to $320 \mathrm{~cm}^{2}$. Transposition flap, rotation flap, removal of osteomyelitic dead bone (sequestrum) and skin grafts were done. Wound size upto $30 \mathrm{~cm}^{2}$ was covered with rotation flap, upto $64 \mathrm{~cm}^{2}$ was covered with transposition flap and more than 64 $\mathrm{cm} 2$ was covered with skin graft. In case of osteomyelitis of outer table of skull bone, skin

1. Md Tariqul Islam, Assistant Professor, Dept. of Burn \& Plastic Surgery, Khulna Medical College \& Hospital.

2. Sk Nishat Abdullah, Junior Consultant, Burn \& Plastic Surgery, Shaheed Sk Abu Naser Specialized Hospital, Khulna.

3. Md Mehedi Newaz, Assistant Professor, Dept. of Orthopedics, Khulna Medical College \& Hospital.

4. Mizanur Rahman, Assistant Professor, Dept. of Paediatric Surgery, Khulna Medical College \& Hospital.

5. Md Ashikur Rahman, Assistant Professor, National Institute of Cancer Research \& Hospital, Dhaka. 
graft was done irrespective of size of wound after removal of sequestrum. All the patients presenting with defect in scalp due to any causes were included in this study. No comorbid illness were considered as exclusion criteria but due to the risk of infection during the expansion period, tissue expansion was excluded from primary reconstruction and due to lack of logistic support, reconstruction with free flap was also excluded in this study. Patients were included in the study after obtaining an informed consent. All the study variables were collected on pre designed proforma such as age, sex, procedure performed and complications noted.

\section{Results}

Among 16 patients; 11 were male and 05 were females. Most of the patients age ranged from 31-40 years (Table I). The size of the defect ranged from $6 \mathrm{~cm} 2$ to $320 \mathrm{~cm} .{ }^{2}$

\section{Table I}

Distribution of age

\begin{tabular}{lccl}
\hline $\begin{array}{l}\text { Age Range } \\
\text { (year) }\end{array}$ & Number & $\%$ & Causes of the Defect \\
\hline $0-10$ & 2 & 12.5 & Road Traffic Accident \\
$11-20$ & 3 & 18.75 & Electric Burn \\
$21-30$ & 2 & 12.5 & Road Traffic Accident \\
$31-40$ & 5 & 31.25 & Multiple cause* \\
$41-50$ & 1 & 6.25 & Road Traffic Accident \\
$51-60$ & 2 & 12.5 & Excision of scalp malignancy \\
$61-70$ & 1 & 6.25 & Excision of scalp malignancy \\
\hline
\end{tabular}

* Machinery injury (2), Road Traffic Accident (1), Electric Burn (1), Excision of scalp malignancy (1)

The common causes of the scalp defects were Road Traffic Accident (6 cases), Scalp cancer (4 cases), Burn ( 4 cases) and machinery Injuries ( 2 cases), shown in Table II.

Table II

Distribution of the cause of the defects

\begin{tabular}{lcc}
\hline Cause of the defect & $\begin{array}{c}\text { Number } \\
\text { of cases }\end{array}$ & $\%$ \\
\hline Road Traffic Accident & 6 & 37.5 \\
Malignancy & 4 & 25 \\
Electric Burn & 4 & 25 \\
Machinery Injury & 2 & 12.5 \\
\hline
\end{tabular}

The transposition flap was the most common procedure performed $(37.5 \%)$, while rotation flaps $(31.25 \%)$ was the 2nd commonest procedure performed in this series of patients (Table III). The postoperative complications seen in this series
Table III

Distribution of the procedures performed for scalp reconstruction

\begin{tabular}{lcc}
\hline Name of the Procedure & $\begin{array}{c}\text { No. of } \\
\text { the cases }\end{array}$ & $\%$ \\
\hline Skin graft & 3 & 18.75 \\
Transposition flap & 6 & 37.5 \\
Rotation flap & 5 & 31.25 \\
$\begin{array}{l}\text { Removal of osteomyelitic bone } \\
\text { \& skin graft }\end{array}$ & 2 & 12.5 \\
\hline
\end{tabular}

includes partial graft loss in 2 cases (skin graft), Marginal necrosis in 1 case (transposition flap) and alopecia in 11 cases (Table IV). Alopecia was common in all types of reconstruction (Fig. 1a, b) except reconstruction with rotation flap (Fig. 2a, b). Post operative alopecia developed in grafted area.

Table IV

Complications of the procedure

\begin{tabular}{lcc}
\hline Name of complications & $\begin{array}{c}\text { No. of } \\
\text { the cases }\end{array}$ & $\%$ \\
\hline Partial graft loss & 2 & 12.5 \\
Marginal flap necrosis & 1 & 6.25 \\
Alopecia & 11 & 68.75 \\
\hline
\end{tabular}

\section{Discussion}

Knowledge of scalp anatomy is essential for planning scalp reconstruction. Although the soft tissues are highly vascularized, the pattern of circulation is subject to interruption at several locations. One characteristic of the scalp is the limited elasticity compared to other tissues. This limited elasticity is primarily the result of the underlying galea and pericranium. This inelastic characteristic limits options for primary closure except in relatively small defects. Wide undermining and creation of large rotation flaps are often required even for relatively small defects.

In scalp reconstruction, as in other regions of the body, it remains useful to approach wound closure using the concept of a reconstructive ladder first considering primary closure followed by skin grafts, local flaps, regional flaps and ultimately free tissue transfer. 5

Every option has some advantages and disadvantages. Reconstruction with skin graft is easy to perform, can cover very large defects, have ample donar area, needs less time and less efficiency. But skin graft can't be used when skull is exposed and it causes post operative alopecia. In this study skin graft was done for large scalp defect without having skull exposed. In all cases of skin graft, alopecia developed. Different types of flaps have the advantages to replace tissue with 
like tissue, are more durable in terms of coverage. Transposition flap can cover a large area but the donar area needs skin graft which causes alopecia.11 In rotation flaps, donar areas are primarily closed which can avoid alopecia. But the

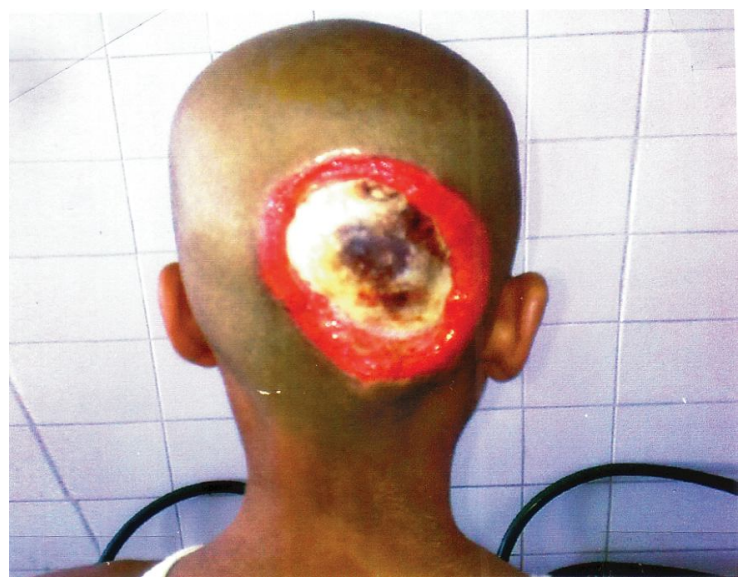

Fig. 1 (a) : Pre-operative alloplastic reconstruction. 6 In this study tissue expansion was excluded from primary reconstruction due to the risk of infection during the expansion period. Numerous free flaps have been described for scalp reconstruction. ${ }^{7-10}$ But

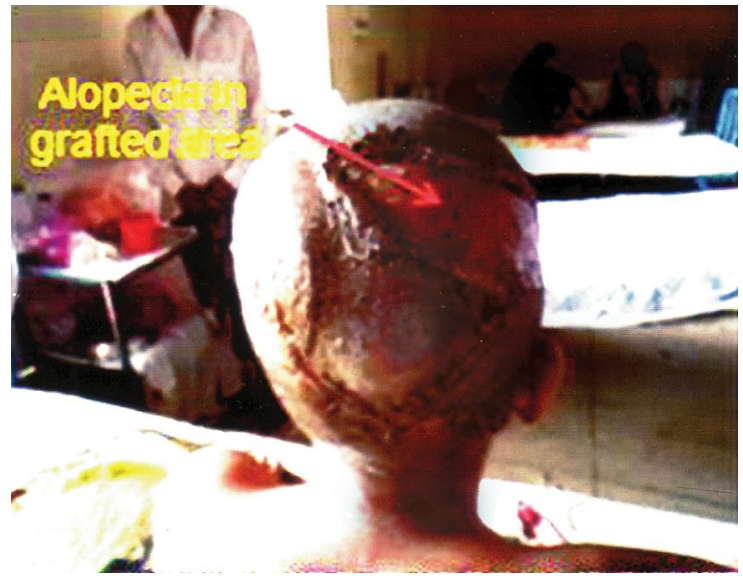

Fig. 1 (b) : Post operative

Fig. 1: Post electric burn scalp defect with exposed skull in occipital region covered with transposition flap.

rotation flaps need a long operative time, precise planning and of course surgical skill. In this study rotation flaps didn't cause any alopecia. But rotation flap can't be used for large defect.

Tissue expansion is an excellent method for scalp reconstruction. When the adjacent scalp is expanded by insertion of a tissue expander and used as a flap, it provides the coverage of large wounds without disturbing hair growth as it uses

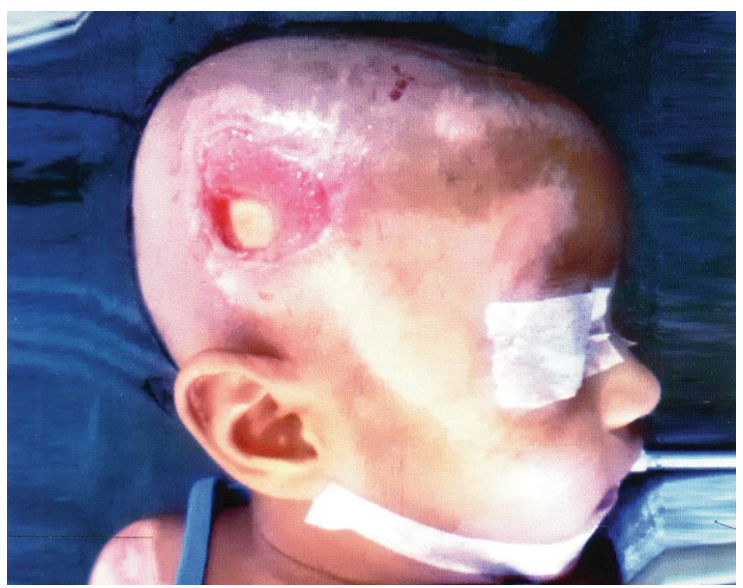

Fig. 2 (a) : Pre-operative free flaps also cause alopecia. In this study, reconstruction with free flap was not done due to lack of logistic support. Drilling of skull bone to invite granulation tissue was practiced once upon a time. But it is a risky procedure having a chance of trauma to meninges and brain. Moreover it's a lengthy procedure to form granulation tissue. In our study we didn't performed this procedure. Some patients present at late with osteomyelitis of



Fig. 2 (b) : Post operative

Fig. 2: Post traumatic-soft tissue defect in right temporal region covered with rotation flap

the hair bearing skin leaving no donor defect. Unfortunately, immediate skin expansion is rarely possible in the oncologic patient. In addition, the use of this technique is associated with high complication rates in patients with a history of previous radiation, infection, or exposed skull. In this situations skin graft or flap reconstruction can be done after removal of osteomyelytic outer table of skull bone. In this study osteomyelytic outer table of skull bone was removed and the defect was skin grafted over granulated wound in $2(12.5 \%)$ cases. But this 
also caused alopecia. Alopecia was not found only in reconstruction with rotation flap.

\section{Conclusion}

It can be concluded that local scalp flaps are better than other flap. Among local flaps many procedures cause alopecia. In difficult situations, microsurgical tissue transfer (Free flaps) appears the best option but it also causes alopecia and donor site morbidity. Among local flaps rotation flaps brings the best outcome in terms of durability and aesthetic acceptability.

\section{References}

I. Hossain MZ, Sarker B, Lenin LK, Hanna A, Dhar LK. Scalp Reconstruction Following High Voltage Electric Burn. Bangladesh Journal of Plastic Surgery 2012; 3: $49-52$.

2. Tamas C, Popa L, Turliuc D, Morosanu C, Lazar M. Surgical reconstruction in scalp defects. Clinics of Plastic and Reconstructive Surgery 2005; 1: 83-86.

3. Tolhurst DE, Carstens MH, Greco RJ, et A The surgical anatomy of the scalp. Plastic and reconstructive Surgery.1991; 87: 603-612.
4. Raposio E, Nordstrom RE, Santi PL. Undermining of the scalp: quantitative effects. Plastic and Reconstructive Surgery 1998; 101: 1218-1222.

5. Newman MI, Hanasono MM, Disa A et al. Scalp Reconstruction: A 15 Year Experience. Annals of Plastic Surgery 2004; 52: 501-506.

6. Hussussian G, Reece GP. Microsurgical scalp reconstruction in the patient with cancer. Plastic and Reconstructive Surgery 2002; 109: 1828-1834.

7. loannides $\mathrm{C}$, Fossion $\mathrm{E}$, McGrouther $\mathrm{AD}$. Reconstruction for large defects of the scalp and cranium.J Craniomaxillofac Surg 1999; 27: 145-152.

8. Lutz BS, Wei FC, Chen HC, et al. Reconstruction of scalp defects with free flaps in 30 cases. Br J Plast Surg 1998; 51: 186-190.

9. McCombe D, Donato R., Hofer SO, et al. Free flaps in the treatment of locally advanced malignancy of the scalp and forehead. Ann Plast Surg 2002; 48: 600-606.

10. Frodel JL, AhIstrom K. Reconstruction of complex scalp defects. Arch Facial Plast Surg 2004; 6: 54-60.

11. Lesavoy MA, Dubrow TJ, Schwartz RJ, et al. Management of large scalp defects with local pedicle flaps. PlastReconstr Surg 1993; 91: 783-790. 